\title{
Incorporation of fatty acids from fish oil and olive oil into colonic mucosal lipids and effects upon eicosanoid synthesis in inflammatory bowel disease
}

\author{
K Hillier, R Jewell, L Dorrell, C L Smith
}

\begin{abstract}
The incorporation of the fatty acids in fish and olive oil into the colonic mucosa of patients with inflammatory bowel disease was examined during 12 weeks' dietary supplementation with the oils, and the influence on colonic mucosal prostaglandin and thromboxane generation was measured. With a dietary supplement of $18 \mathrm{~g}$ fish oil daily, concentrations of the major polyunsaturated fatty acids in fish oil, eicosapentaenoic acid and docosahexaenoic acid, were significantly raised in mucosal lipids. The first time these were measured, after three weeks' supplementation, the mean increases in eicosapentaenoic and docosahexaenoic acid were seven fold and 1.5 fold respectively, and these increases were maintained during the 12 week study. Arachidonic acid values fell throughout the study and this reduction was significant at 12 weeks. Mucosal prostaglandin $\mathbf{E}_{2}\left(\mathbf{P G E}_{2}\right)$, thromboxane $B_{2}$, and 6-keto prostaglandin $F_{1 \alpha}$ synthesis were suppressed, and this reached significance $(p<0.05)$ at three and 12 weeks for $\mathrm{PGE}_{2}$ and at 12 weeks for thromboxane $B_{2}$. The predominant fatty acid in olive oil is oleic acid. Supplementation with $18 \mathrm{~g} /$ day resulted in a significant increase in oleic acid in colonic mucosa at 12 weeks $(p<0.05)$ and a fall in stearic acid and docosahexaenoic acid; there was no significant change in eicosanoid synthesis. It is concluded that colonic lipids and prostaglandin and thromboxane synthesis can be readily altered by dietary supplementation with fish oil. The extent of incorporation of the fatty acids present in oils is dependent upon the individual fatty acid.
\end{abstract}

It is claimed that diets enriched in fish lipids offer therapeutic benefit in several diseases. Epidemiological studies have shown that a high intake of fish oils may be related to a reduced incidence of cardiovascular and asthmatic disease. ${ }^{1}$ In clinical studies, supplementation with fish oils has led to improvements in patients with psoriasis ${ }^{2}$ and rheumatoid arthritis, ${ }^{3}$ reductions in plasma triglyceride and cholesterol concentrations, and in thrombocyte aggregability. ${ }^{4}$ It has been suggested that fish oil lipids lead to improvements in ulcerative colitis, ${ }^{5}$ but this has not been confirmed. ${ }^{6}$ Feeding studies in laboratory animals have also shown improvements in induced atherosclerosis, ${ }^{7}$ lupus, ${ }^{8}$ and colitis. ${ }^{9}$

In normal western diets the preponderant intake of oils from vegetable sources such as sunflowers provides relatively high amounts of linoleic acid (C18:2) (Fig 1). This can be metab- olised to arachidonic acid (C20:4) and hence to dienoic eicosanoids such as prostaglandin $\mathrm{E}_{2}\left(\mathrm{PGE}_{2}\right)$, thromboxane $\mathrm{A}_{2}\left(\mathrm{TxA}_{2}\right)$, and leukotriene $\mathrm{C}_{4} \quad\left(\mathrm{LTC}_{4}\right)$. The predominant polyunsaturated fatty acids present in fish oils are eicosapentaenoic acid (C20:5) and docosahexaenoic acid (C22:6). C20:5, which is absent in vegetable oils, has been shown to be metabolised to a family of trienoic eicosanoids, for example, $\mathrm{PGE}_{3}, \mathrm{TxA}_{3}$, and also $\mathrm{LTC}_{5}$ which have subtly different biological properties to the dienoic eicosanoids and $\mathrm{LTC}_{4}$ derived from arachidonic acid. It is hypothesised that fish oils may reduce inflammation via the production of relatively larger amounts of 3 series prostaglandins and 5 series leukotrienes which possess reduced inflammatory potential. In addition, fish oils may inhibit the cyclo-oxygenase enzymes that form prostaglandins and thromboxane. ${ }^{10}$

The synthesis of several eicosanoids is increased in inflammatory bowel disease and may be responsible for some of the pathophysiological features of the disease. Mucosal samples taken from patients with active disease have increased capacity to synthesis $\mathrm{PGE}_{2}, 1$ $\mathrm{TxA}_{2},{ }^{12}$ and leukotrienes. ${ }^{1415}$

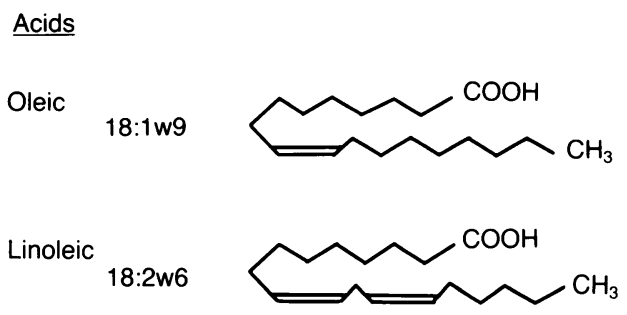

Arachidonic 20:4w6

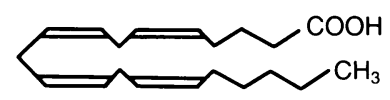

Eicosapentaenoic 20:5w3

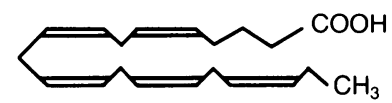

Docosahexaenoic 22:6w3

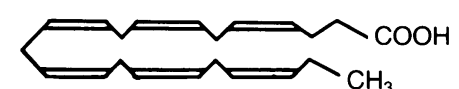

Figure 1: Fatty acids in fish and olive oils. The figures refer to the number of double bonds in the fatty acid and $w(n)$ describes the position of the first double bond from the methyl group. Oleic acid is present in vegetable and some animal fats. Linoleic acid is present in vegatable oils and is converted to arachidonic acid which is present in vegetable and animal sources in very small amounts only. Eicosapentaenoic acid and docosahexaenoic acid are present in fish lipids. 
The increased eicosanoids present may result, in part, from the large amounts of arachidonic acid (C20:4) found in the mucosa of patients with inflammatory bowel disease compared with normal mucosa. ${ }^{16}{ }^{17}$ It has been hypothesised that modulation of excessive formation of some eicosanoids may be beneficial in inflammatory bowel disease; benefit may accrue both from reducing the directly pro-inflammatory effects inherent in some eicosanoids but also indirectly as some eicosanoids can act to increase the synthesis or action of other inflammatory mediators. In addition, increased supplementation of diets with fish oils has been shown to reduce interleukin formation, ${ }^{18}$ free radical generation, ${ }^{19}$ and platelet activating factor formation, ${ }^{20}$ all of which are increased in inflammatory bowel disease. Despite these wide ranging effects and therapeutic potential, no studies on the incorporation of dietary fish oil fatty acids in large bowel mucosa in man have been reported.

We examined the incorporation of fatty acids from fish oil (Maxepa) into the mucosa of the large bowel in patients with inflammatory bowel disease during 12 weeks of dietary supplementation. This was compared with the incorporation from fatty acids in olive oil and effects of the supplements on prostaglandin, thromboxane, and prostacyclin synthesis were also assessed. A preliminary communication of results in 13 patients has previously been presented in abstract form. ${ }^{21}$

\section{Patients and methods}

Twenty patients with active ulcerative colitis or Crohn's colitis were admitted to the study. On admission, mucosal tissue specimens were taken from inflamed colonic sites during colonoscopy. One biopsy specimen was immediately frozen in liquid nitrogen and stored at $-70^{\circ} \mathrm{C}$ until analysed for eicosanoids and fatty acids. Histological examination of a second specimen verified the diagnosis.

Patients were allocated to receive $6 \times 1 \mathrm{~g}$ capsules of fish oil (Maxepa) or olive oil three times a day on a random open basis for a 12 week study period. Patients were asked not to change their conventional diet. The total consumption per day of $18 \mathrm{~g}$ Maxepa provided $3.2 \mathrm{~g}$ daily C20:5, $2 \cdot 2 \mathrm{~g}$ daily C22:6, $1 \cdot 7 \mathrm{~g}$ daily palmitoleic acid $(\mathrm{C} 16: 1)$, and $2.4 \mathrm{~g}$ daily oleic acid $(\mathrm{C} 18: 1)$. The olive oil consumption provided $13.9 \mathrm{~g}$ per day C18:1. No restrictions were put on the intake of drugs. No patient was taking non-steroidal anti-inflammatory drugs.

Eleven patients received Maxepa; nine had active ulcerative colitis and two active Crohn's colitis. There were eight men and three women with an age range of 32-79 years. All patients were receiving between $15-30 \mathrm{mg}$ prednisolone daily on admission to the trial, reducing to 0-20 $\mathrm{mg}$ after 12 weeks. Six were taking additional sulphasalazine or mesalazine.

Nine patients received olive oil; all had active ulcerative colitis. There were six men and three women and the age range was 34-79 years. All patients were receiving between $15-40 \mathrm{mg}$ prednisolone daily on admission to the trial, reducing to $0-20 \mathrm{mg}$ after 12 weeks. Six were taking additional sulphasalazine or mesalazine on admission to the study.

In both groups, the protocol followed reduced steroids every three weeks if improvement in the patient's condition was maintained. At a dosage of greater than $20 \mathrm{mg}$ per day, reduction was by $10 \mathrm{mg}$, and at a dosage of less than $20 \mathrm{mg}$, by $5 \mathrm{mg}$.

Patients attended the clinic three, six, and 12 weeks after admission to the study for reassessment and colonoscopy. The study was approved by the Southampton District Ethical Committee and informed consent was obtained from the patients.

\section{Dietary oils}

The batches of Maxepa used contained 13.5\% C18:1, 18.0\% C20:5, and 12\% C22:6. The olive oil contained $77 \cdot 3 \% \mathrm{C} 18: 1,7 \cdot 2 \% \mathrm{C} 18: 2$, and trace amounts of other fatty acids. Both fish oil and olive oil contained $1 \mathrm{IU}$ vitamin $\mathrm{E}$ per $\mathrm{ml}$ and $0 \cdot 2 \% \mathrm{w} / \mathrm{w}$ natural peppermint oil.

\section{Fatty acid analysis}

Transmethylation of total lipids was by a modification of the method of Folch et al. ${ }^{22}$ Portions of biopsy specimens were rinsed with $1 \mathrm{ml} 1 \cdot 15 \%$ $\mathrm{KCl}$ and homogenised in $1 \mathrm{ml}$ chloroform/ methanol $(2: 1 \mathrm{v} / \mathrm{v})$. The homogeniser was washed with an additional $1 \mathrm{ml}$ chloroform/ methanol and the total homogenate stood at room temperature in $2 \mathrm{ml}$ chloroform/methanol for 20 minutes. It was then centrifuged at $1000 \mathrm{~g}$ for five minutes. The supernatant was removed and evaporated to dryness under nitrogen at $30^{\circ} \mathrm{C}$. The residue was reconstituted in $20 \mu \mathrm{l}$ dry methanol, and after the addition of $20 \mu \mathrm{l}$ sodium methoxide $(2 \cdot 2 \%$ in dry methanol $)$ was retained under nitrogen for 30 minutes. To end the reaction, $20 \mu \mathrm{l}$ acetylchloride/dry methanol $(1: 19 \mathrm{v} / \mathrm{v})$ was added and the tubes were retained under nitrogen for a further five minutes. The samples were extracted twice with $100 \mu \mathrm{l}$ hexane, the pooled upper layers were evaporated to dryness, and the residue was reconstituted in $50 \mu \mathrm{l}$ hexane. Samples were stored under nitrogen at $-20^{\circ} \mathrm{C}$ until analysed.

Fatty acid methyl esters were analysed by gas liquid chromatography on a Packard 438A chromatograph (wall coated, open tubular fused silica capillary column, length $51 \mathrm{~m}$; internal diameter $0.22 \mathrm{~mm}$; liquid phase CP SIL88, film thickness $0.21 \mu \mathrm{m}$; carrier gas $\mathrm{H}_{2}$; split-flow ratio $100: 1$; column flow $1 \mathrm{ml} /$ minute; injection temperature $270^{\circ} \mathrm{C}$; FID $300^{\circ} \mathrm{C}$; temperature programme $175^{\circ} \mathrm{C}$ for three minutes, increased to $210^{\circ} \mathrm{C}$ at $5^{\circ} \mathrm{C} /$ minute and maintained at $210^{\circ} \mathrm{C}$ for 25 minutes). Peak identification was by comparison with a known standard mixture, each profile being recorded on a Spectra Physics SP4270 integrator. Fatty acid values were expressed as a percentage of the total major fatty acids present.

Eicosanoid synthesis and analysis Biopsies were preincubated with $1 \mathrm{ml}$ Krebs 
(saturated with $95 \% \mathrm{O}_{2} / \mathrm{CO}_{2}$ ) at $37^{\circ} \mathrm{C}$ for five minutes. The samples were then centrifuged at $8700 \mathrm{~g}$ for one minute and the supernatant discarded. The tissue was resuspended in Krebs solution $(1 \mathrm{ml})$ and further incubated at $37^{\circ} \mathrm{C}$ for 30 minutes. Each sample was again centrifuged and either $\left[{ }^{3} \mathrm{H}\right] \mathrm{PGE}_{2}$ or $\left[{ }^{3} \mathrm{H}\right] \mathrm{PGF} \mathrm{F}_{2 \alpha}(6000 \mathrm{dpm})$ added to monitor procedural losses. The supernatant was then extracted, and analysed for $\mathrm{PGE}_{2}, \mathrm{TxB}_{2}$, or 6-keto-PGF ${ }_{1 \alpha}$ by radioimmunoassay as described by de la Hunt et al..$^{23}$ The eicosanoids were eluted from the octadecasilyl silica microcolumns with distilled diethyl ether $(10 \mathrm{ml})$. The ether was evaporated to dryness under nitrogen at $30^{\circ} \mathrm{C}$ and the residue reconstituted in $3 \mathrm{ml} 0.1 \mathrm{~mol} / 1$ phosphate buffer $(\mathrm{pH}$ $7 \cdot 5)$. The samples were stored at $-20^{\circ} \mathrm{C}$ until analysed.

Procedural losses were assessed by monitoring the recoveries of added recovery isotope and values corrected for losses; $\mathrm{PGE}_{2}$ and $\mathrm{PGF}_{2 \mathrm{a}}$ recoveries were mean (SD) $79(6) \%(n=25)$ and $89(7) \%(n=47)$ respectively. In previous studies using gastric mucosa, the recoveries of $\mathrm{PGE}_{2}$, $\mathrm{PGF}_{2 \alpha}, 6$-keto-PGF $1 \alpha$, and $\mathrm{TxB}_{2}$ were in the range $81-91 \%(n=10-48)$ and did not differ significantly from each other or from recoveries in the present study. The eicosanoids $\mathrm{PGE}_{2}$, 6-keto-PGF $1 \alpha$ (stable metabolite of $\mathrm{PGI}_{2}$ ), and $\mathrm{TxB}_{2}$ (stable metabolite of $\mathrm{TxA}_{2}$ ) were assayed by radioimmunoassay using highly selective antisera. After suitable dilution, each sample was measured at two concentrations and the final values expressed as ng eicosanoid synthesised/ $\mathrm{mg}$ protein/30 minutes incubation. This technique gives an index of the capacity of the tissue to synthesise prostaglandins and thromboxanes and does not reflect tissue concentrations at the time of sampling. Metabolism of prostaglandins and $\mathrm{TxB}_{2}$ is negligible in this incubation system. Blank values obtained by passing Krebs solution through the entire procedure were included with each assay. The mean (SD) blank values for $0 \cdot 1$ $\mathrm{ml}$ of the $3 \mathrm{ml}$ reconstituted extracts were $\mathrm{PGE}_{2}$

TABLE I The mean (SEM) percentage fatty acid composition of human colonic mucosa in patients with active inflammatory bowel disease during 12 weeks' dietary supplementation with enriched fish oil capsules (Maxepa) or olive oil. The second figure in parentheses is number of patients

\begin{tabular}{lclll}
\hline Fatty acid & Week 0 & Week 3 & Week 6 & Week 12 \\
\hline C20:4 - olive oil & $8 \cdot 5(1 \cdot 0)(9)$ & $8 \cdot 6(1 \cdot 3)(8)$ & $7 \cdot 5(2 \cdot 0)(6)$ & $5 \cdot 1(1 \cdot 3)(5)$ \\
C20:4 - fish oil & $10 \cdot 0(2 \cdot 9)(11)$ & $7 \cdot 9(1 \cdot 0)(10)$ & $8 \cdot 3(0 \cdot 7)(8)$ & $5 \cdot 6(0 \cdot 8)(10) \dagger$ \\
C20:5 - olive oil & $0 \cdot 29(0 \cdot 05)(8)$ & $0 \cdot 36(0 \cdot 04)(8)$ & $0 \cdot 38(0 \cdot 1)(7)$ & $0 \cdot 2(0 \cdot 1)(5)$ \\
C20:5 - fish oil & $0 \cdot 44(0 \cdot 06)(11)$ & $3 \cdot 1(0 \cdot 5)(10) \dagger$ & $3 \cdot 2(0 \cdot 7)(8) \dagger$ & $3 \cdot 1(0 \cdot 5)(10) \dagger$ \\
C22:6 - olive oil & $1 \cdot 7(0 \cdot 2)(8)$ & $1 \cdot 7(0 \cdot 2)(8)$ & $1 \cdot 7(0 \cdot 2)(7)$ & $1 \cdot 0(0 \cdot 1)(5)^{\star}$ \\
C22:6 - fish oil & $2 \cdot 1(0 \cdot 2)(11)$ & $3 \cdot 3(0 \cdot 3)(10) \dagger$ & $3 \cdot 1(0 \cdot 4)(8)^{\star}$ & $2 \cdot 9(0 \cdot 3)(10)$ \\
C18:0 - olive oil & $12 \cdot 9(1 \cdot 1)(9)$ & $12 \cdot 9(1 \cdot 3)(8)$ & $14 \cdot 0(1 \cdot 4)(7)$ & $9 \cdot 4(1 \cdot 3)(5)^{\star}$ \\
C18:0 - fish oil & $13 \cdot 2(0 \cdot 7)(11)$ & $13 \cdot 6(1 \cdot 0)(10)$ & $14 \cdot 2(0 \cdot 9)(8)$ & $13 \cdot 4(0 \cdot 9)(10)$ \\
C18:1 - olive oil & $21 \cdot 7(1 \cdot 9)(9)$ & $22 \cdot 1(2 \cdot 6)(8)$ & $20 \cdot 9(2 \cdot 5)(7)$ & $29 \cdot 9(2 \cdot 7)(5)^{\star}$ \\
C18:1 - fish oil & $19 \cdot 5(1 \cdot 4)(11)$ & $19 \cdot 6(1 \cdot 6)(10)$ & $17 \cdot 3(1 \cdot 6)(8)$ & $19 \cdot 0(1 \cdot 9)(10)$ \\
C20:3 - olive oil & $1.9(0 \cdot 3)(9)$ & $1 \cdot 8(0 \cdot 3)(8)$ & $2 \cdot 0(0 \cdot 4)(7)$ & $1 \cdot 3(0 \cdot 5)(5)$ \\
C20:3 - fish oil & $1 \cdot 8(0 \cdot 2)(11)$ & $1 \cdot 1(0 \cdot 1)(10) \dagger$ & $1 \cdot 25(0 \cdot 1)(8)^{\star}$ & $1 \cdot 2(0 \cdot 2)(10)$ \\
\hline
\end{tabular}

Patients took $6 \mathrm{~g}$ Maxepa or olive oil three times daily.

$\star=p<0.05, \dagger=p<0.01$ using Wilcoxon's ranking test and refer to comparison with values at entry to the trial (0 weeks). C20:4=arachidonic acid; C20:5=eicosapentaenoic acid; C22:6 docosahexaenoic acid; $\mathrm{C} 18: 0=$ stearic acid; $\mathrm{C} 18: 1=$ oleic acid; $\mathrm{C} 20: 3=$ dihomo- $\gamma$-linolenic acid; $\mathrm{C} 14: 0=$ myristic acid C16:0=palmitic acid; $\mathrm{C} 16: 1=$ palmitoleic; $\mathrm{C} 18: 2=$ linoleic acid

For clarity some fatty acids which showed no change through the 12 week period have been omitted. Values on entry to the study were as follows with the figures in the fish oil group shown in brackets C14:0,1.4 (0.2) $(1 \cdot 4(0 \cdot 2)) ; \mathrm{Cl} 6: 0,19 \cdot 1(1 \cdot 1)(19 \cdot 8(0 \cdot 5)) ; \mathrm{C} 16: 1,1 \cdot 7(0 \cdot 6)(1 \cdot 3(0 \cdot 3)) ; \mathrm{C} 18: 2,11 \cdot 9(1 \cdot 2)$ $(10 \cdot 9(0 \cdot 8)) . n=9$ for the olive oil group and $n=11$ for the fish oil group. The data are expressed for the individual fatty acids as a percentage of the total fatty acids analysed including those that did not alte through the 12 week study period.

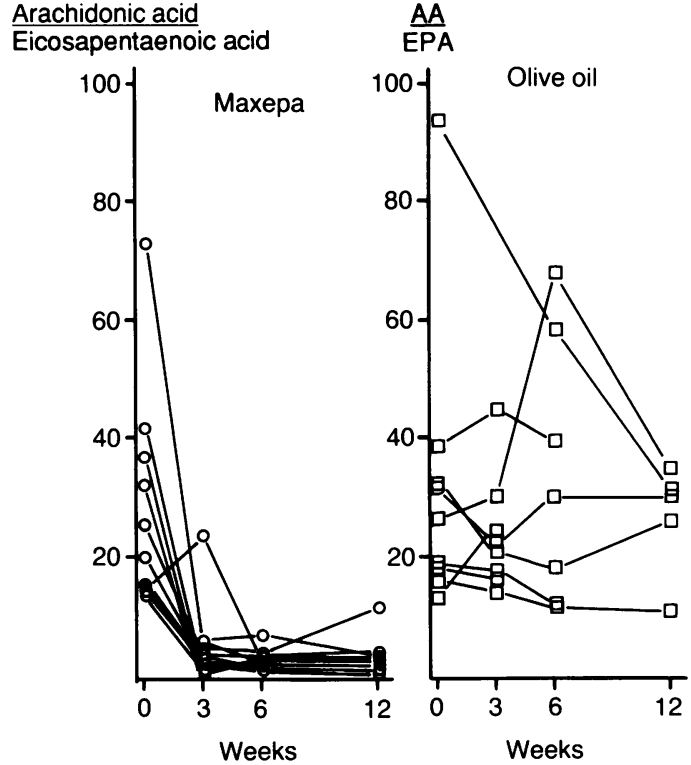

Figure 2: Ratio of arachidonic acid $(A A)$ :eicosapentaenoic acid (EPA) in colonic mucosa of individual patients taking $18 \mathrm{~g}$ fish oil daily or $18 \mathrm{~g}$ olive oil daily. In the fish oil group the ratio fell significantly by three weeks and remained suppressed throughout the 12 week study $(p<0.01$ at three, six, and 12 weeks compared with 0 weeks using Wilcoxon's rank test). Changes in the olive oil group were not significant.

$(1 \cdot 4(2 \cdot 0)) \mathrm{pg}, 6$-keto-PGF $1 \alpha(1 \cdot 1(1 \cdot 9)) \mathrm{pg}$, and $\mathrm{TxB}_{2}(0 \cdot 7(0 \cdot 8)) \mathrm{pg}$. The intra-assay coefficients of variation were $\mathrm{PGE}_{2} 9 \%(\mathrm{n}=6), 6$-keto- $\mathrm{PGF}_{1 \alpha}$ $6 \%(n=6)$, and $\mathrm{TxB}_{2} 6 \%(n=6)$. The respective interassay coefficients of variation were $9 \%$ $(n=4), 10 \%(n=4)$, and $9 \%(n=4)$.

\section{TOTAL PROTEIN ANALYSIS}

Each biopsy specimen was hydrolysed in $0 \cdot 1 \mathrm{~N}$ $\mathrm{NaOH}(1 \mathrm{ml})$ at $50^{\circ} \mathrm{C}$ for approximately five hours and analysed for total protein content by a modification of the method by Lowry et al. ${ }^{24}$

\section{Results}

FATTY ACID STUDIES

The results in ulcerative colitis and Crohn's disease patients were not different, and data are therefore presented together. Both fish oil and olive oil were well accepted, with only one patient complaining about the taste of fish oil. Table I shows the percentage fatty acid distribution in mucosa from patients taking fish oil or olive oil for up to 12 weeks. In the Maxepa group between eight and 10 patients of the 11 recruited attended regularly during the study period. In the olive oil group five patients of nine recruited continued for the full 12 weeks study period.

On admission to the study (week 0 ) there was no significant difference in the percentages of individual fatty acids in the colonic mucosa of patients allocated to the fish oil or the olive oil group. The distribution of fatty acids in colonic mucosal lipids at week 0 before beginning the dietary supplements is noticeable in that C20:5 and C22:6, which are prevalent in fish oils, make up only a small percentage of total fatty acids present, whereas $\mathrm{C} 18: 1$, present in large amounts in olive oil makes up about $20 \%$ of total 
TABLE II Mean (SEM) prostaglandin $(P G)$ and thromboxane $(T x)$ synthesis $(n g / m g$ protein in a 30 minute incubation) by colonic mucosa in patients with active inflammatory bowel disease during 12 weeks' dietary supplementation with enriched fish oil capsules (Maxepa) or olive oil. Figures in second set of parentheses is number of patients

\begin{tabular}{|c|c|c|c|c|}
\hline & Week 0 & Week 3 & Week 6 & Week 12 \\
\hline $\begin{array}{l}\mathrm{PGE}_{2} \text { - olive oil } \\
\mathrm{PGE}_{2} \text { - fish oil }\end{array}$ & $\begin{array}{l}22 \cdot 7(4 \cdot 6)(9) \\
25 \cdot 1(4 \cdot 7)(11)\end{array}$ & $\begin{array}{l}40 \cdot 5(13 \cdot 1)(8) \\
11 \cdot 2(2 \cdot 1)(9)^{\star}\end{array}$ & $\begin{array}{l}17 \cdot 9(7 \cdot 2)(5) \\
14 \cdot 0(2 \cdot 7)(8)\end{array}$ & $\begin{array}{l}25 \cdot 3(0 \cdot 45)(3) \\
10 \cdot 8(2 \cdot 6)(9)^{\star}\end{array}$ \\
\hline $\begin{array}{l}\mathrm{TxB}_{2}-\text { olive oil } \\
\mathrm{TxB}_{2}-\text { fish oil }\end{array}$ & $\begin{array}{l}10 \cdot 5(2 \cdot 1)(9) \\
10 \cdot 3(1 \cdot 4)(11)\end{array}$ & $\begin{array}{l}8 \cdot 7(1 \cdot 6)(8) \\
7 \cdot 8(1 \cdot 4)(9)\end{array}$ & $\begin{array}{r}10 \cdot 1(3 \cdot 9)(5) \\
8 \cdot 0(1 \cdot 3)(8)\end{array}$ & $\begin{array}{l}7 \cdot 6(0.96)(3) \\
6 \cdot 4(1 \cdot 0)(9)^{\star}\end{array}$ \\
\hline $\begin{array}{l}6 \text { keto- } F_{1 u}-\text { olive oil } \\
6 \text { keto- } F_{1 \alpha}-\text { fish oil }\end{array}$ & $\begin{array}{c}8 \cdot 9(2 \cdot 0)(9) \\
13 \cdot 1(3 \cdot 2)(11)\end{array}$ & $\begin{array}{r}14.4(3.6)(8) \\
6.6(1.5)(9)\end{array}$ & $\begin{array}{r}10 \cdot 0(4 \cdot 5)(5) \\
7 \cdot 8(1 \cdot 6)(8)\end{array}$ & $\begin{array}{r}16 \cdot 8(4 \cdot 3)(3) \\
7 \cdot 7(1 \cdot 9)(9)\end{array}$ \\
\hline
\end{tabular}

$\star=\mathrm{p}<0.05$ Wilcoxon's rank test and refers to comparison with values at entry to the trial $(0$ weeks).

mucosal fatty acids. The main unsaturated fatty acids present were C18:1, C18:2, and C20:4 while the main saturated fatty acids present were palmitic acid (C16:0) and C18:0. Table I shows that fish oil consumption had a considerable effect on $\mathrm{C} 20: 5$ and $\mathrm{C} 22: 6$ values. After three weeks, C20:5 had increased sevenfold $(p<0.01)$ and $\mathrm{C} 22: 6$ almost doubled $(\mathrm{p}<0 \cdot 01)$. The increases were maintained during the study period. In the olive oil group, there were no significant changes in $\mathrm{C} 20: 5$ and $\mathrm{C} 22: 6$. The range of $\mathrm{C} 20: 5$ on admission was $0 \cdot 14-0.7 \%$ and after three weeks it was $0 \cdot 86-4.9 \%$. These data suggest that compliance in taking the capsules was acceptable. The individual patient values for the ratio of C20:4/C20:5 are shown in Figure 2. At entry to the study, the ratio of $\mathrm{C} 20: 4 / \mathrm{C} 20: 5$ in 10 of the 11 patients in the fish oil group ranged from $14 \cdot 1-42 \cdot 0$, but in one patient the ratio was $74 \cdot 2$. In the olive oil group the ratio in eight out of nine patients was $14 \cdot 2-39 \cdot 0$ but in one patient it was $92 \cdot 1$. There was no dietary or other understood reason for high $\mathrm{C} 20: 4 / \mathrm{C} 20: 5$ ratios in these two patients. The ratio of $\mathrm{C} 20: 4 / \mathrm{C} 20: 5$ fell precipitously in all but one patient and remained low during the 12 week study period. Dihomo- $\gamma$ linolenic acid (C20:3) was also significantly reduced in the fish oil group at three weeks and six weeks. In the olive oil group there was no increase in the C18:1 values in the colonic mucosa until 12 weeks supplementation $(\mathrm{p}<0.05)$, despite the fact that the diet provided $13.9 \mathrm{~g}$ per day $\mathrm{C} 18: 1$ in olive oil. There was also a fall in C18:0 and C22:6 after 12 weeks in patients taking olive oil.

Table II shows the prostaglandin and thromboxane synthesis by mucosal specimens in both groups. On admission to the study (week 0 ) there was no significant difference in eicosanoid synthesis between the fish oil and olive oil groups. The fish oil diet resulted in a significant reduction in $\mathrm{PGE}_{2}$ synthesis at three weeks and 12 weeks, although the decline at six weeks did not reach significance. At six weeks, however, all patients tested had $\mathrm{PGE}_{2}$ values lower than the individual patient values on admission. $\mathbf{P G I}_{2}$ synthesis (measured as the stable metabolite 6-keto-PGF ${ }_{1 \alpha}$ ) was lower than the individual patient's admission values in seven of nine, six of eight, and seven of nine patients at three, six, and 12 weeks after taking fish oil but the figures did not reach statistical significance. $\mathrm{TxA}_{2}$ synthesis was lower than individual patient's admission values in seven of nine, seven of eight, and eight of nine patients at three, six, and 12 weeks after taking fish oil but this only reached a level of significance of $\mathrm{p}<0.05$ after 12 weeks. The olive oil diet had no significant effect on the synthesis of prostaglandins or thromboxanes; the sample size at 12 weeks was, however, small.

The current study was not performed primarily as a clinical trial to assess therapeutic benefit. Nonetheless, after three weeks, nine of 10 taking fish oil were improved endoscopically and symptomatically and six of eight taking olive oil were improved. There was no difference in the steroid intake in the two groups.

\section{Discussion}

Supplementation of diets with fish oil significantly and relatively rapidly increased the incorporation of $\mathrm{C} 20: 5$ and $\mathrm{C} 22: 6$ fatty acids in colon mucosa lipids and there was, at the same time, a small but significant fall $(p<0.05)$ in dihomo- $\gamma$-linolenic acid (C20:3). At this time we do not have information on the cell types into which these fatty acids are incorporated or if the incorporation is uniform in different cell types.

There is considerable variability in the incorporation of dietary supplements of fatty acids into mucosal lipids. For example, we found no increase in the amounts of $\mathrm{Cl} 18: 1$ in the colon mucosal lipids in patients taking fish oil despite this fatty acid making up $13.5 \%$ of the total fatty acids present and providing $2 \cdot 4 \mathrm{~g}$ per day $\mathrm{C} 18: 1$. Even with the provision of $13.9 \mathrm{~g} \mathrm{C18:1}$ per day in olive oil, a significant increase in colonic mucosa was not seen until 12 weeks of dietary supplementation. In laboratory animal studies, ${ }^{23}$ supplementation of the diets of rats with corn oil (46\% C18:2) resulted in an increase in C18:2 in gastric mucosal lipids and liver and yet duodenal mucosa showed no increase in C18:2. The reasons for this are, as yet, unclear but this illustrates that every tissue, and indeed cell type, is likely to have a very individual pattern of fatty acid incorporation from dietary oils.

Three weeks after starting the fish oil supplement, the increases in C20:5 and C22:6 in the mucosa had reached their optimum; as no earlier samples were taken we cannot say precisely when the peak was achieved. It is also possible that C20:4, which was significantly reduced after 12 weeks' fish oil supplementation, may continue to fall after 12 weeks as fatty acid compartments with a slow turnover become progressively depleted of this fatty acid.

The relatively rapid exchange between plasma C20:5 and colon mucosal phospholipids noted in this study seems to be much slower in other cells such as platelets and red cells. ${ }^{25}$ In the latter study, volunteers took consecutive incremental doses of cod liver oil of $10,20,40$, and then $20 \mathrm{ml}$ per day changing from one dose level to another after four weeks. Platelet and red cell concentrations of C20:5 rose only slowly when doses were increased and in red cells even continued to increase despite a lowering of the dose to $20 \mathrm{ml}$ per day after 12 weeks. The return to normal fatty acid concentrations after stopping the cod liver oil took several weeks. In contrast to the relatively rapid changes seen in colonic mucosal fatty acids in patients taking fish oil, significant changes in $\mathrm{C} 18: 1$ and $\mathrm{C} 18: 0$ values were not seen until between six and 12 weeks after beginning 
supplementation in those taking olive oil. These data indicate that there are lipid pools where turnover of fatty acids proceed at different rates; they also suggest that loading doses of fatty acids may effectively increase the fatty acid concentration in lipid pools, which can then be maintained on lower continuing doses. The long term effects of fish oil supplementation have also been described by Endres et al..$^{18}$ During a six week feeding study with fish oil, interleukin-1 production by peripheral blood mononuclear cells was suppressed. On stopping the fish oil diet interleukin-1 production fell further until the nadir was reached 10 weeks after ceasing supplementation and had returned to normal 10 weeks after that.

The therapeutic potential, if any, of fish oil in the treatment of inflammatory bowel disease is unproved. In a small open study, 12 weeks' administration of fish oil improved patients' symptoms and the histological appearance of the rectal mucosa. During the 12 weeks, sulphasalazine and steroids were withdrawn. ${ }^{5}$ In a controlled double blind clinical trial carried out over one year, fish oil or olive oil were randomly administered. There was no difference in relapse rate or percentage of time spent in remission, and steroid treatment was not different in the two groups. ${ }^{6}$ It is questionable whether olive oil is a suitable 'placebo' in such a study. Although there are, as yet, no data to substantiate this, it is possible that the consumption of large amounts of C18:1 may have biological effects.

In an animal model, where a large bowel inflammatory colitis was induced in rats by the administration of trinitrobenzene sulphonic acid, fish oil, but not olive oil, reduced the chronic severity of the lesions, ${ }^{9}$ although the severity of the initial injury produced was similar in the olive oil and fish oil groups.

The pharmacological effects of fish oil are such that it might be expected to benefit inflammatory bowel disease. It causes a suppression of the production of many potentially damaging mediators that have been shown to be produced in excess within the colonic mucosal cells in these disorders. Interleukin- $1,{ }^{2627} \mathrm{TxB}_{2}{ }^{12}{ }^{13}$ leukotrienes, ${ }^{1+28}$ platelet activating factor, ${ }^{29}$ and prostaglandins ${ }^{1130}$ are all produced in greater amounts compared with normal mucosa and Hawkey et $a l^{13}$ have also shown that there is an increased ratio of thromboxane to $\mathrm{PGI}_{2}$ in the colonic mucosa in Crohn's disease. It is of importance that some mediators that are produced act synergistically but others are, in fact, antagonistic; for example, $\mathrm{PGE}_{2}$ has been shown to inhibit interleukin synthesis. Further studies should determine whether different fats and varied dosage schedules have the ability to modulate selectively the production of particular mediators and whether this can favourably influence inflammatory bowel disease.

We thank Seven Seas Health Care for supplies of Maxepa and olive oil capsules. Financial support from the National Association for Colitis and Crohn's Diseases and the Leverhulme Trust is gratefully acknowledged.

1 Kromann N, Green A. Epidemiological studies in the Upernavik district of Greenland: incidence of some chronic diseases 1950-1974. Acta Med Scand 1980; 208: 401-6.
2 Bittiner SB, Tucker WF, Cartwright I, Bleehen SS. A double blind, randomised, placebo-controlled trial of fish oil in psoriasis. Lancet 1988; i: 378-80.

3 Kremer JM, Jubiz W, Michalek A, et al. fish oil fatty acid supplementation in active rheumatoid arthritis. Ann Intern Med 1987; 106: 497-502.

4 Goodnight SH, Harris WS, Connor WE, Illingworth DR. Polyunsaturated fatty acids, hyperlipidaemia and thrombosis. Arteriosclerosis 1982; 2: 87-113.

5 McCall TB, O'Leary D, Bloomfield J, O'Morain CA. Therapeutic potential of fish oil in the treatment of ulcerative colitis. Aliment Pharmacol Therap 1989; 333: 415-24.

6 Hawthorne AB, Daneshmend TK, Hawkey CJ, Shaheen MZ, Edwards TJ. Fish oil in ulcerative colitis: final results of a controlled trial. Proceedings of 7 th International Conference on Prostaglandins and Related Compounds. May 28-June 1, Prostaglandins and

7 Davis HR, Bridenstine RT, Vesselinovitch D, Wisler RW. Fish oil inhibits development of arterosclerosis in rhesus monkey. Arteriosclerosis 1987; 7: 441-9.

8 Kelley VE, Ferretti A, Izui A, Strom TB. A fish oil diet rich in eicosapentaenoic acid reduces cyclooxygenase metabolites and suppresses lupus in MRL-1pr mice. F Immunol 1987; 134: 1914-9.

9 Vilaseca J, Salas A, Guarner F, Rodriguez R, Martinez M, Malagelada J-R. Dietary fish oil reduces progression of chronic inflammatory lesions in a rat model of granulomatous colitis. Gut 1990; 31: 539-44.

10 Needleman P, Raz A, Minkes M, Ferendelli JA, Sprecher H. Triene prostaglandins: prostacyclin and thromboxane Triene prostaglandins: prostacyclin and thromboxane
synthesis and unique biological properties. Proc Natl Acad synthesis and unique

11 Pacheco S, Hillier K, Smith CL. Inflammatory bowel disease: the in vitro effects of sulphasalazine and other agents on prostaglandin synthesis by human rectal mucosa. Braz $\mathcal{J}$ Med Biol 1987; 20: 221-30.

12 Ligumsky M, Karmeli F, Sharon P, Zor D, Rachmilewitz D. Enhanced thromboxane $\mathrm{A}_{2}$ and prostacyclin production by cultured rectal mucosa in ulcerative colitis and its inhibition by steroids and sulphasalazine. Gastroenterology 1981; 81: 444-9.

13 Hawkey CJ, Karmeli F, Rachmilowitz D. Imbalance of prostacyclin and thromboxane synthesis in Crohn's disease. prostacyclin and throm

14 Sharon P, Stenson WF. Enhanced synthesis of leukotriene B4 by colonic mucosa in inflammatory bowel disease. Gastroenterology 1984; 86: 453-60.

15 Lauritsen K, Laursen LS, Bukhave K, Rask-Madsen J. The in vivo effects of orally administered prednisolone on prostaglandin and leucotriene production in ulcerative colitis. Gut 1987; 28: 1095-9.

16 Pacheco S, Hillier K, Smith CL. Increased arachidonic acid levels in phospholipids of human colonic mucosa in inflammatory bowel disease. Clin Sci 1987; 73: 361-4.

17 Nishida T, Miwa $H$, Shigematsu A, Yamamoto $M$, Iida $M$, Fujishima $M$. Increased arachidonic acid composition of phospholipids in colonic mucosa from patients with active phospholipids in colonic mucosa from

18 Endres S, Ghorbani R, Kelley VE, et al. The effect of dietary supplementation with $n-3$ polyunsaturated fatty acids on the synthesis of interleukin-1 and tumour necrosis factor by mononuclear cells. N Engl f Med 1989; 320: 265-71.

19 Lands WEM, Miller JF, Rich S. Influence of dietary fish oils on plasma lipid hydroperoxides. Adv Prostaglandin Thromboxane Leukotriene Res 1987; 17: 876-9.

20 Croft KD, Sturm MJ, Codde JP, Vandongen R, Beilin LJ. Dietary fish oils reduce plasma levels of platelet activating factor precursor (lyso-PAF) in rats. Life $S_{c i} 1986 ; 38$ : $1875-$ 82.

21 Hillier K, Dorrell L, Jewell R, Smith CL. Effect of dietary marine oil on human colon mucosa lipid fatty acids and prostaglandin synthesis in patients with inflammatory bowel prostaglandin synthesis in patients with inflammatory bowel
disease. In: Lands WEM, ed. Polyunsaturated fatty acids and disease. In: Lands WEM, ed. Polyunsaturated fatty acid
eicosanoids. Champaign, Illinois: AOCS, 1987: 481 .

22 Folch J, Lee M, Swane-Stanley GH. A simple method for the isolation and purification of total lipids from animal tissues. f Biol Chem 1957; 226: 497-509.

23 Hunt de la MN, Hillier K, Jewell R. Modification of upper gastro-intestinal prostaglandin synthesis by dietary fatty acids. Prostaglandins 1988; 35: 597-608.

24 Lowry OH, Rosebrough NJ, Farr L, Randall RJ. Protein measurement with the Folin phenol reagent. 7 Biol Chem 1951; 193: 265-75.

25 Shacky von C, Fischer S, Weber PC. Long term effects of dietary marine omega-3 fatty acids upon plasma and cellular lipids, platelet function and eicosanoid function in human. lipids, platelet function and Invest 1985; 76: 1626-31.

26 Ligumsky M, Simon PL, Karmeli F, Rachmilewitz D. Role of interleukin 1 in inflammatory bowel disease-enhanced of interleukin 1 in inflammatory bowel disease-enha

27 Mahida YR, Wu K, Jewell DP. Enhanced production of interleukin $\mathrm{BB}$ by mononuclear cells isolated from mucosa with active ulcerative colitis and Crohn's disease. Gut 1989; 30: $835-8$.

28 Hawthorne AB, Edwards TJ, Filipowicz B, Daneshmend TK, Hawkey CJ. Reduced leukotriene $B_{4}$ and increased LTB synthesis in ulcerative, colitis with fish oil. Gastroenterology 1989; 96: A201.

29 Eliakim R, Karmeli F, Razin E, Rachmilewitz D. Role of platelet activating factor in ulcerative colitis. Gastroenterology 1988; 95: 1167-72.

30 Sharon P, Ligumsky M, Rachmilewitz D, Zor U. Role of prostaglandins in ulcerative colitis: enhanced production during active disease and inhibition by sulfasalazine. Gastroenterology 1978; 75: 638-40. 